\title{
A New Diverting Agent Material for Hydraulic Fracturing Treatment in Oil and Gas Industry
}

\author{
Bo $\mathrm{CAI}^{1, \mathrm{a}}$, Guoqiang $\mathrm{BI}^{2, \mathrm{~b}}$,Jinping QIU ${ }^{3, \mathrm{c}}$ and Chunming $\mathrm{HE}^{4, \mathrm{~d}}$ \\ ${ }^{1}$ PetroChina Research Institute of Petroleum Exploration and Development, Langfang China \\ ${ }^{2}$ PetroChina Research Institute of Petroleum Exploration and Development, Langfang China \\ ${ }^{3}$ PetroChina Exploration and Production Company,Beijing, China \\ 4PetroChina Research Institute of Petroleum Exploration and Development, Langfang China \\ aboocai123@126.com¹ biguoqiang@126.com, 'cqiujinp@163.com, ${ }^{\mathrm{d}}$ hehun@126.com
}

\begin{abstract}
In-fissure divert fracturing technology, in which diverting agent is added. It can create new branch fractures and micro fractures, increase the area of fluid-release and achieve the goal of production and injection increase. This paper introduces a new diverting agent material with different kinds of petroleum resins. A series of evaluation including compatibility, efficiency and dissolved time was put forward. The results showed that the soluble rate of this agent is from $6 \mathrm{~h}$ to $12 \mathrm{~h}$ and with increasing temperature and prolonging dissolved time, soluble rate reach $96 \%$ at $110^{\circ} \mathrm{C}$ indicated good solubility. The critical flow velocity of sand production increases more than $30 \sim 60$ times with adding fiber. The highest breakthrough pressure can reach $0.5 \mathrm{MPa}$ in $10 \mathrm{~cm}$ cores containing $9 \%$ diverting agent in the fracturing fluid. Meanwhile, it has minimal impact on flow conductivity .It had good flow back after treatment the viscosity was 13-54 mPa.s. Moreover, a special instrument was introduced to evaluate the performances of fracture conductivity and diverting. More than 24 treatments with this new material in X oil field have been performed with encouraging results with an average post-fracturing rate $11 \mathrm{~m}^{3} / \mathrm{d}$. It has great influences on new chemical material for improving complex fractures net-work of hydraulic fracturing in tight oil and gas reservoirs.
\end{abstract}

\section{Introduction}

Tight oil is a petroleum play that consists of light crude oil contained in petroleum-bearing formations of low permeability, often shale or tight sandstone. It should not be confused with tight oil, which is oil manufactured from oil shale by heating kerogen-rich rock[1]. As early as 1936, some scholars put forward the water soluble / oil soluble $\mathrm{CaCl}_{2}$ Salt. The application of temporary diverting agent in oil field work solved the early fracturing .In the traditional section, the equipment quantity is large, the production

*Corresponding author: boocai123@126.com 
cost is high, and the operation efficiency is high. In recent years, volume fracturing technology is now playing an important part in the development of these kinds of reservoirs owing to it can increase fracture complexity (Fig.1). Diverting agent material can achieve the aim of diversion via stress interference and has become the mainly technology to increase the fracture complexity (Fig.2). In 2005, Wang put forward a method of adding large diameter of proppants or dissolvable wax balls during hydraulic fracturing treatment in the low permeability reservoirs. However, the large diameter proppants are invalid because of the high temperature, small fracture width. Temporary plugging agent is one of the key technology for in-fissure divert fracturing, most of the plugging agent is oil-soluble, and is not suitable for the high water cut oil wells and injection wells In this paper, we obtained a new diverting agent named $\mathrm{Zn}-1$ based on original diverting materials. This diverting agent material can improve the effect of diverting. After application of eight wells was successfully carried out, the result shows that the new diverting materials meet the demand of in-fissure divert fracturing technology and achieve the goal of production. It can also be provided as a new technological in the construction of high temperature wells, complicated wells and other wells with sand-adding difficulty.

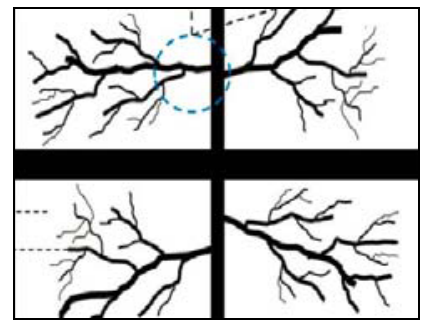

Fig.1 Fracture complexity using diverting agent material

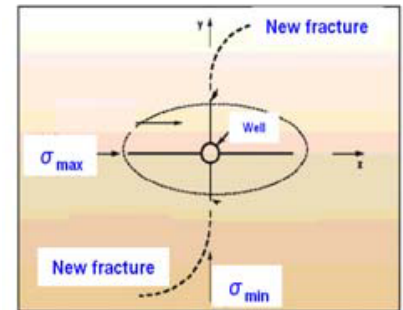

Fig.2 Sketch map of fracture diversion

\section{Materials and Synthesis Process}

The basic raw materials are rosin, paraffin, asphalt, potassium chloride, powder, EVA and quartzs and Petroleum resin A, hydrocarbon resin B, catalyst etc. Different kinds of petroleum resins (PR) and hydrocarbon resins (PA) were chosen as the main materials. The main materials of the new temporary diverting agent material are PR and PA with the ratio of 1:4. PR is easily smashed and with large rigidity and its softening point is $135 \sim 150{ }^{\circ} \mathrm{C}$. The concentration is from 0.2 to 1 and the fineness is from 200 to 50 mesh. The Speed control agent is $\mathrm{T}$ with the concentration of $0.01 \sim 0.04$. The diverting agent is yellow particles with the density is $1.1 \sim 1.3 \mathrm{~g} / \mathrm{cm}^{3}[2]$. Oil-water mixture in water containing more than $50 \%$. The solubility of the solution is more than $90 \%$, and the compressive strength is $22 \mathrm{MPa}$. By further adhesive, we form the ideal uniform spherical particles. And by concentrating these particles to granule, we finally made the $\mathrm{Zn}-1$ (Fig 3). Such temporary diverting agent not only has excellent water solubility, but also does not cause pollution to the reservoir.The same layer blocking also has other diverting technology.
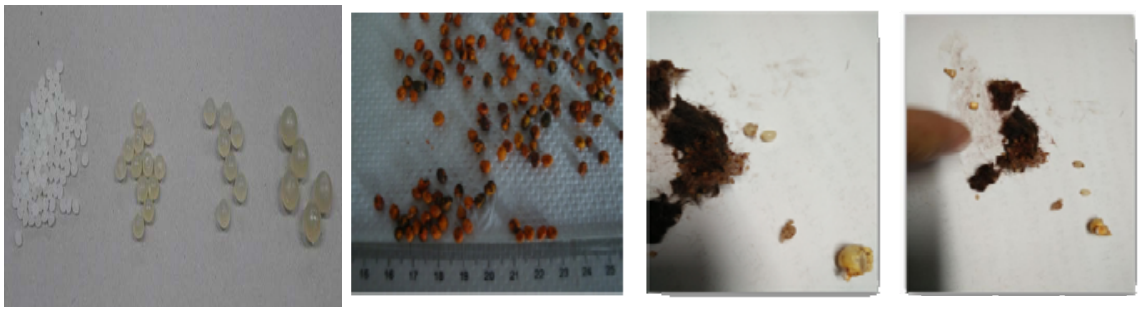

Fig.3 Picture of diverting agents 


\section{Capability Evaluation}

In the past, the temperature resistance of temporary diverting agent is generally less than 80 degrees, so the effect of plugging in the middle and high temperature will be restricted [3]. Study of new temporary diverting agent temperature effect, 20-120 ${ }^{\circ} \mathrm{C}$ design, within 2 hours of conventional temporary plugging agent and new temporary plugging agent of dissolution rate, is shown in Fig 4, below $80{ }^{\circ} \mathrm{C}$ two temporary plugging agent dissolved effect is quite, conventional temporary plugging agent is dissolved rate slightly higher, but when the temperature exceeded $80{ }^{\circ} \mathrm{C}$, conventional temporary plugging agent dissolution rate was significantly higher than that of the new temporary plugging agent of dissolution rate, indicating that new temporary plugging agent of anti-temperature performance better. Under the different formulations, temporary plugging agent concentration dispersion performance evaluation experiments, from the table 1 results show that when with $0.2 \%$ concentration of polyacrylamide solution carrying liquid, can make 15\%ZD temporary plugging agent suspension stability time of 12 hours (Fig.5), so be sure to carry liquid guar gum concentration of $0.2 \%$. Plugging rate reached $99 \%$ ( Table 1 ).

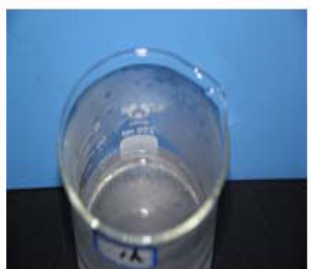

After 1 hour

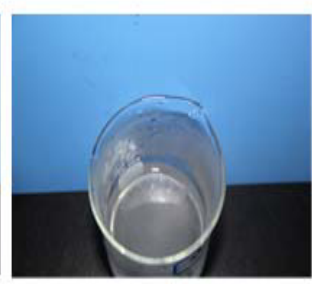

After 2 hours

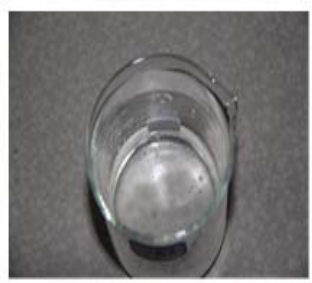

After 6 hours

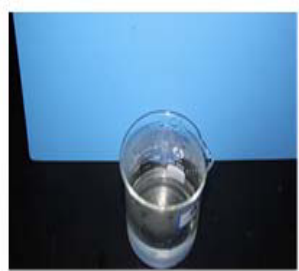

After 8 hours

Fig4. 1-2 mm diverting agent's solubility in $120{ }^{\circ} \mathrm{C}$ circumstance

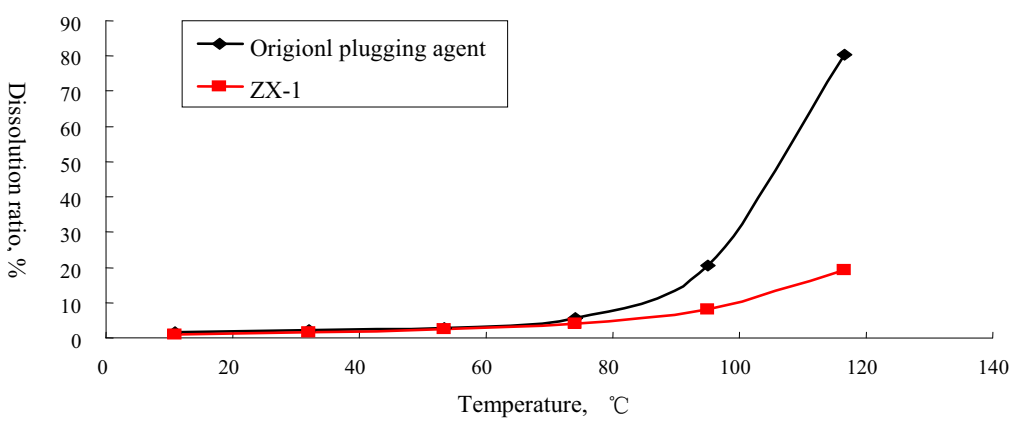

Fig.5 Dissolve comparison between the original diverting agent and Zn-1 
Table 1 Sedimentation Of Different Liquid Concentration At Different Time

\begin{tabular}{|c|c|c|c|c|c|c|c|}
\hline \multirow[b]{2}{*}{ Medium } & \multirow{2}{*}{$\begin{array}{l}\text { Diverting agent } \\
\text { content } \\
(\%)\end{array}$} & \multicolumn{6}{|c|}{ Dispersion in different time duration } \\
\hline & & $10 \mathrm{~min}$ & $1 \mathrm{~h}$ & $\begin{array}{l}8 \\
\mathrm{~h}\end{array}$ & $12 \mathrm{~h}$ & $24 \mathrm{~h}$ & $36 \mathrm{~h}$ \\
\hline Water & 15 & \multicolumn{2}{|c|}{ Particle Sediment } & \multicolumn{4}{|c|}{ Upside become clear } \\
\hline $\begin{array}{c}\text { Solution of } \\
0.1 \% \mathrm{HP}\end{array}$ & 15 & \multicolumn{2}{|c|}{$\begin{array}{l}\text { uniformly } \\
\text { distributed }\end{array}$} & \multicolumn{4}{|c|}{ Sediment } \\
\hline $\begin{array}{l}\text { Solution of } \\
0.2 \% \mathrm{HP}\end{array}$ & 15 & \multicolumn{4}{|c|}{$\begin{array}{l}\text { uniformly distributed, well } \\
\text { suspended }\end{array}$} & \multicolumn{2}{|c|}{$\begin{array}{l}\text { large particles } \\
\text { sediment }\end{array}$} \\
\hline $\begin{array}{l}\text { Solution of } \\
0.3 \% \mathrm{HP}\end{array}$ & 15 & \multicolumn{6}{|c|}{ uniformly distributed, well suspended } \\
\hline $\begin{array}{l}\text { Solution of } \\
0.4 \% \mathrm{HP}\end{array}$ & 15 & \multicolumn{6}{|c|}{ Large viscosity, Disperse difficult } \\
\hline
\end{tabular}

In general, the plugging agent of the liquid concentration, particle size and temporary plugging agent of the pressure bearing capacity and the ability to dissolve closely related to [4]. The higher the concentration, the greater the intensity. The larger particles, compressive worse; particles the rules more surface area, degree of maturation, the better, the formation of temporary plugging agent strength is high [5]. The temporary plugging agent and agent combination of compressive strength of support are confirmed by using different mesh size of the temporary plugging agent and 70 ceramic support agent combination matching relationship. Table 2 shows that: with the increase in the number of entries, compressive performance increase, but increases to 120 mesh after compression effect increases smaller, so the 120 mesh temporary plugging agent $+70 \mathrm{c}$ mesh ceramic composite compressive of best(Table 2).

Table 2 Pressure Resistant Experiment Of Diverting Agent (10\% Concentrate And Proppant)

\begin{tabular}{|c|c|c|c|}
\hline \multicolumn{2}{|c|}{ Combination } & \multirow{2}{*}{$\begin{array}{l}\text { Temperature } \\
\left({ }^{\circ} \mathrm{C}\right)\end{array}$} & \multirow{2}{*}{$\begin{array}{c}\text { Pressure resistance } \\
(\mathrm{MPa})\end{array}$} \\
\hline $\begin{array}{l}\text { Diverting Agent } \\
\text { (mesh) }\end{array}$ & $\begin{array}{c}\text { Ceramsite } \\
\text { (mesh) }\end{array}$ & & \\
\hline \multirow{3}{*}{80} & \multirow{3}{*}{70} & 30 & 36.4 \\
\hline & & 60 & 35.3 \\
\hline & & 90 & 35.3 \\
\hline \multirow{3}{*}{100} & \multirow{3}{*}{70} & 30 & 48.5 \\
\hline & & 60 & 48.3 \\
\hline & & 90 & 48.2 \\
\hline \multirow{3}{*}{120} & \multirow{3}{*}{70} & 30 & 62.7 \\
\hline & & 60 & 62.5 \\
\hline & & 90 & 62.5 \\
\hline \multirow{3}{*}{200} & \multirow{3}{*}{70} & 30 & 65.7 \\
\hline & & 60 & 65.5 \\
\hline & & 90 & 65.5 \\
\hline
\end{tabular}




\section{Impact Resistance}

In the past, the experiment of plugging performance of temporary plugging agent was only made for artificial The seam of the core was continuously pressurized to investigate the breakthrough pressure without consideration [6].The compressive strength of the temporary plugging agent core under the change of instantaneous pressure. In this paper, through the design of experiments, simulation of the process of steering fracturing, injection fracturing. The impact of liquid on the temporary plugging agent was determined.

According to the field data, the formation fracture pressure is $34 \mathrm{MPa}$. The in-situ stress field evaluation of the external steering fracturing shows that the in-situ stress field can be divided into Stress reversal area and stress non inversion region, stress reversal area (crack steering Area) the radius is not more than $10 \mathrm{~m}$. Temporary plugging agent for plugging cracks in the sealed length $10 \mathrm{~m}$, the gel breakthrough pressure gradient is greater than $3.4 \mathrm{MPa} / \mathrm{m}$, When the fracturing fluid is injected into the fracturing fluid, the temporary plugging agent is not punctured [7]. The plugging agent combined with $30 \mathrm{~cm} \times 30 \mathrm{~cm} \times 30 \mathrm{~cm}$ core physical simulation experiment device, were determined not to join the temporary plugging agent and adding temporary plugging agent of crack closure effect [8]. The results show that by use of the temporary plugging agent after the artificial crack closure rate reached $95 \%$, artificial cracks exist obvious steering characteristics, realize the steering effect of cracks.

\section{Field Test}

Taking $\mathrm{x}$ horizontal well as an example for the first time application of tight oil reservoir, the horizontal section length of $1050 \mathrm{~m}$, effective reservoir porosity $8.1 \%, 0.15 \mathrm{mD}$, effective permeability of formation pore pressure of $29.0 \mathrm{MPa}$, horizontal principal stress difference of 3.2 MPa. The section is 6 paragraph, the total fluid volume of $4400 \mathrm{~m}^{3}, 330 \mathrm{~m}^{3}$, sand adding temporary diverting agent $4 \mathrm{t}$ and pressure after micro seismic monitoring results show that by means of temporary plugging agent temporary plugging and large displacement volume fracturing technology, realize the artificial fracture stress interference, the artificial fracture cracks appeared in various places to $[9,10]$ The length 1.5 times higher than that of previous methods, shows that using the diverter and volume under paragraph 6 fracturing of fracturing technology to achieve the optimal volume, than in the past did not consider temporary plugging to fracturing technology to save three or four segment interval, reduce the cost by more than $29 \%$, after the pressure effect increased 2.5 times, for horizontal well section more temporary plugging into volume optimization improved important technical guidance (fig.6). The product field application time in more than 10 Wells shows that the diverter oil-soluble reached more than $95 \%$, over the construction of combined with proppant to effect is increased by 1.5 times, after transforming effect is increased by 2.1 times, to improve crack under the unconventional reservoir volume fracturing model complexity choice to provide new material. 


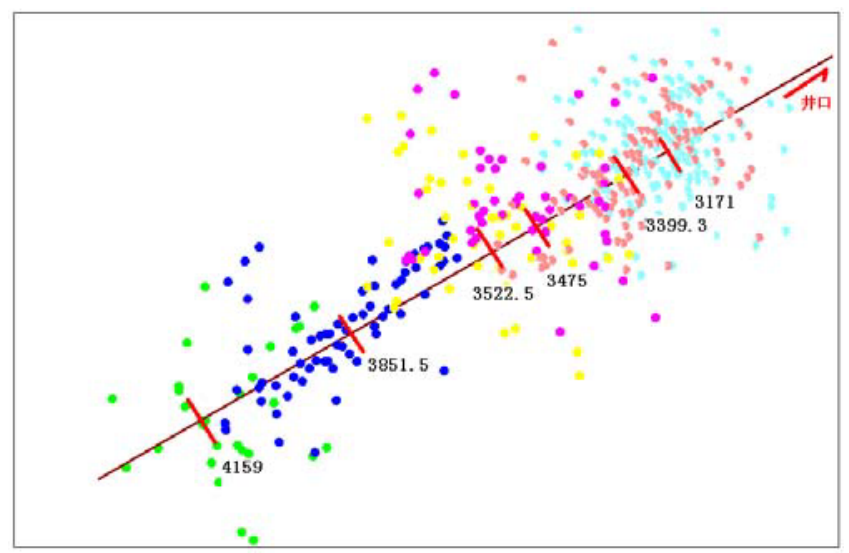

Fig.6 Fracturing curve of well $\mathrm{X}$

\section{Summary and Conclusions}

(1) To improve the degree of complication of fracture to fracturing technology has significant reuse of unconventional oil and gas resources exploration and development. The past of agent has the shortcoming of big construction risk, low temperature resistant ability, steering difficult problems, This paper put forward a new chemical synthesis of material, improves the heat resistance and plugging strength $t$, combined with the optimized by particle size and the comprehensive utilization of proppant improve steering effect. This kind of diverting agent is temperature resistant, easy swerve and well worked.

(2) Through the heat resistance performance, the dispersion degree of new type diverter and carrier performance test, shows that the new diverter and heat-resistant properties from before $80{ }^{\circ} \mathrm{C}$ to $120{ }^{\circ} \mathrm{C}$; When do carrier fluid with $0.2 \%$ concentration of polyacrylamide solution, can make $15 \% \mathrm{lh}-\mathrm{Z}-150$ temporary plugging agent suspension stability time up to 12 hours, can further reduce the dosage of fracturing fluid thickener concentration. Compatibility and performance is good..

(3) Field application more than 10 times the well confirmed the diverter and success rate of design technology to improve the effect of steering and construction effect is obvious, oil-soluble achieve $95 \%$ above, through the organic combination of proppant will shift to the effect increased by 1.5 times, after transforming effect is increased by 2.1 times, to improve crack under the unconventional reservoir volume fracturing model complexity choice to provide new material. This kind of diverting agent can be chosen as the new material to increase the fracture complexity.

\section{References}

1. Jia Chengzao, Zou Caineng,Li Jianzhong, et al. Assessment criteria,main types,basic features and resource prospects of the tight oil in China[J].Acta Petrolei Sinica, 2012, 33 (3) : 343-349.

2. Cai Bo, Zhang Yiming, Jin Fengming, et al.Research on acid fracturing system with improving stimulated reservoir[J].Drilling Fluid \& Completion Fluid, 2013，30（1）: 69-72.

3. Wang Yongchang,Jiang Biwu, Ma yanfeng,et al. Study of repeated fracturing technology in low-permeable sand oil reservoir in AnSai oilfield[J].Oil Drilling \& Production Technology,2005,27(5):78-80. 
4. Sun Zandong, Jia Chengzao, Li Xiangfang, et al. Unconventional oil \& gas exploration and development: upper volume [M]. Beijing: Petroleum Industry Press, 2011: 1-150.

5. Cai bo, Ding Yunhong,Lv Yongjun.Optimizing flow coupling in complex artificial fracture network systems $[\mathrm{J}]$. Journal of China University of Mining\&Technology,2014,43(3):470-474.

6. Xiong Ying,Jiang Guandeng,et al.Research of the lab evaluation technique about oil dissolve resin temporary diverting agent[J]. Drilling \& Prodution Technology, 2000, 22(4): 78-80.

7. Cai Bo, Ding Yunhong, Lv Yongjun, et al. A case study of hydraulic fractures optimization in heavy oil[R], SPE 172849,2014.

8. Xianzheng Zhao, Yongjun Li , Bo Cai, et al. Study of an Oil Soluble Diverting Agent for hydraulic fracturing treatment in Tight Oil and gas reservoirs[R], SPE 178142,2015.

9. Ding Yunhong, Xianzheng Zhao, Bo Cai, et al. A novel massive acid fracturing technique with improving stimulated reservoir volume in HTHP reservoir in China[R],SPE172771,2014.

10. Bo Cai, Wen Zhai, Liwei Wang, xiaohui Qiu, et al. Study and Application of Ultra-temperature Polymer Fluid for Enhanced Stimulation in $\mathrm{HP} / \mathrm{HT}$ Reservoirs[R],SPE177635,2015.

11. Cai Bo,Zhao xianzheng, Shen $\mathrm{Hu}$, et al. Study of hybrid volume fracturing on tight calcilutite-rudstone in Shulu sag reservoirs[J].Acta Petrolei Sinica,2015, 36(S1) :76-82. 